\title{
A Home Health Monitoring System Designed to Support Carers in Their Caring Role
}

\author{
Andrea Taylor, Richard Wilson, Stefan Agamanolis \\ Distance Lab \\ Forres, Scotland \\ \{andrea, richard, stefan\}@distancelab.org
}

\begin{abstract}
In the UK, a 'carer' is someone who, unpaid, looks after a family member, friend or partner who could not manage without them because of frailness, illness or disability. In this paper, we present research on the role of the carer, and describe why it is important to consider carers in the design of new healthcare technology to support people to self care. By self care, we mean supporting people to take more control and responsibility for their own health and well-being. Our contribution is a set of design guidelines for new home monitoring technology. Our guidelines are distilled from a survey distributed to carers in Moray, North East Scotland on sharing health information and a follow-up discussion at a carers forum. We used these guidelines to design a new home monitoring system. The main difference with current systems is that data is primarily shared between carer and cared-for, rather than health professional and patient, and carers are encouraged to use the system to monitor their own health.
\end{abstract}

Keywords-carer; survey; self care; home monitoring

\section{DEFINITION OF CARER}

In the UK, a 'carer' is someone who, unpaid, looks after a family member, friend or partner who could not manage without them because of frailness, illness or disability. Carers may share the same household as the person they care for, or live close-by or far away. The term carer does not include professional care workers who receive payment for looking after someone as part of employment.

\section{INTRODUCTION}

The delivery of healthcare is changing in response to an ageing population, the growth in long-term conditions, and the rising trend in emergency admissions to hospital among older people. Healthcare has been hospital centred and reactive, with the patient as passive recipient and carers undervalued. The evolving model of care emphasises care in the community and self care, with the patient and carers supported as partners.

Self care is about supporting people to take more responsibility for their own health and well-being. There is evidence that self care support can result in beneficial health outcomes for people, lessening the demand on healthcare systems [5], and that people are interested in being more active self carers [4]. New home monitoring technology can support people to self care. Home monitoring systems enable health professionals to remotely monitor patients' vital signs in the patient's own home to look for signs of changes in their condition. The aim is to enable an early intervention and avoid hospital admission. The information may or may not be made available to carers, even though carers play a crucial role in the healthcare of the person they look after.

Three in five people will take on a caring role in their lives [2]. Caring can be stressful, particularly as the carer's role is often ignored by health professionals, and has an impact on the health and well-being of the carer. Carers who provide substantial care are more than twice as likely to suffer from poor health compared to those without caring responsibilities [1]. The costs associated with carers' ill health include the direct cost in treating the carers' own health problems and the indirect cost to the state if the carer is less able to provide care. Thus it is important to involve carers in the healthcare of the person they look after as well as to support carers to keep well themselves.

This paper describes research on the carer phenomenon as uncovered by a survey of carers in a rural part of Scotland. This survey helped us distill a set of design guidelines that later informed the development of a new home monitoring system that supports sharing health information with carers. Carers can also use the system to monitor their own health. Potentially, the system can support carers by helping to keep them informed about the health of the person they care for and in good health themselves, and provide reassurance and peace of mind for distant carers.

\section{CARER'S SURVEY}

We distributed a survey on sharing health information to carers in Moray. Moray is a region in North East Scotland and has a remote and mainly rural population of 87,000 [7]. Moray has an ageing population, and above the national average population of men and women of pensionable age (pensionable age is 65 for men and 60 for women) [7]. According to National Health Service (NHS) Grampian, there may be over 10,000 carers in Moray. Currently, patients need to travel to medical centres for health advice and monitoring; the distances involved can be problematic (access to transport, time off work, cost). Thus the area is a useful 'test-bed' for new healthcare technology that can overcome distance and support self care. 
The survey was distributed to 1200 carers registered with the Moray Carers Project as an insert in an edition of the organisation's newsletter; the Moray Carers Project is an independent voluntary organisation set up by carers to support unpaid carers in Moray. The aim of the survey was to find out more about what carers do, and their relationship with the people they care for. We particularly wanted to find out carers' views on sharing health information. We received 86 returns. According to Moray Carers Project, a one percent response rate is not unusual for "blanket", or general, consultations; their experience is that carers respond better to consultations that will directly affect their situation. The findings from this small and self-selected sample are therefore preliminary.

The survey consisted of ten multiple-choice questions, and a space for free text comments. For each question, respondents could tick one or more boxes as appropriate. For questions 7, 8, and 10, space for free text comments was provided to support answers.

\section{A. Background Information (Questions 1-6)}

Carers were asked about their age, caring responsibilities, and relationship with the people they care for (table 1). Respondents are mostly: adults aged 18-70 years; looking after a partner or relative; sharing the same household as the person they care for; and providing continuous care. The main reason for providing care is longterm illness. The main types of help given are emotional and shopping/paying bills/collecting and delivering medication.

TABLE I. BACKGROUND INFORMATION ON RESPONDENTS

\begin{tabular}{|c|c|c|}
\hline & $\begin{array}{c}\text { Response } \\
\text { Percent }\end{array}$ & $\begin{array}{c}\text { Response } \\
\text { Count }\end{array}$ \\
\hline \multicolumn{3}{|l|}{ Type of carer } \\
\hline Adult & $72.9 \%$ & 62 \\
\hline Older (over 70 yrs) & $24.7 \%$ & 21 \\
\hline Young (under 18 yrs) & $2.4 \%$ & 2 \\
\hline \multicolumn{3}{|l|}{ Relationship to cared-for person } \\
\hline Partner & $47.1 \%$ & 40 \\
\hline Relative & $47.1 \%$ & 40 \\
\hline Friend or neighbour & $5.9 \%$ & 5 \\
\hline \multicolumn{3}{|l|}{ Distance from cared-for person } \\
\hline Same household & $81.0 \%$ & 68 \\
\hline Live close by & $16.7 \%$ & 14 \\
\hline Live far away & $2.4 \%$ & 2 \\
\hline \multicolumn{3}{|l|}{ Time spent caring per week } \\
\hline Continuous & $68.2 \%$ & 58 \\
\hline Varies & $16.5 \%$ & 14 \\
\hline $20+$ hours & $10.6 \%$ & 9 \\
\hline 5-19 hours & $2.4 \%$ & 2 \\
\hline $1-4$ hours & $2.4 \%$ & 2 \\
\hline \multicolumn{3}{|l|}{ Reason/s for providing care } \\
\hline Long-term illness & $48.2 \%$ & 41 \\
\hline Physical or mental illness & $43.5 \%$ & 37 \\
\hline Physical or learning disability & $31.8 \%$ & 27 \\
\hline Old age & $21.2 \%$ & 18 \\
\hline \multicolumn{3}{|l|}{ Type/s of help given } \\
\hline Emotional & $83.7 \%$ & 72 \\
\hline $\begin{array}{l}\text { Shopping/paying bills/collecting } \\
\text { and delivering medication }\end{array}$ & $83.7 \%$ & 72 \\
\hline Jobs around the house & $81.4 \%$ & 70 \\
\hline
\end{tabular}

\begin{tabular}{|l|l|l|}
\hline Preparing/cooking meals & $80.2 \%$ & 69 \\
\hline Personal care & $70.9 \%$ & 61 \\
\hline Transport & $61.6 \%$ & 53 \\
\hline Looking after pets & $29.1 \%$ & 25 \\
\hline Other & $19.8 \%$ & 17 \\
\hline
\end{tabular}

B. Health Monitoring and Sharing Health Information (Questions 7-8)

Carers were asked whether the person they care for uses any self-monitoring products, and if so, whether the results are shared with them. They were also asked if any (other) health information is shared with them (table 2). Just under a third of respondents said that a product is used; the most popular are weighing scales, and blood pressure and blood glucose monitors. The results are mostly shared with carers, and sometimes it is the carer taking the measurements. Twothirds of respondents said the cared-for person shares other personal health information. Typical comments are "Everything as she is dependent on me" and "As my wife we discuss everything".

TABLE II. Usage of Heatlh Monitoring Products AND PREVALENCE OF INFORMATION SHARING

\begin{tabular}{|c|c|c|c|c|}
\hline & $\begin{array}{c}\text { Response } \\
\text { Percent }\end{array}$ & $\begin{array}{l}\text { Response } \\
\text { Count }\end{array}$ & $\begin{array}{c}\text { Response } \\
\text { Percent }\end{array}$ & $\begin{array}{c}\text { Response } \\
\text { Count }\end{array}$ \\
\hline Question & \multicolumn{2}{|c|}{ Yes } & \multicolumn{2}{|c|}{ No } \\
\hline $\begin{array}{l}\text { Does the person you } \\
\text { care for use any } \\
\text { products to monitor } \\
\text { their health? }\end{array}$ & $30.5 \%$ & 25 & $69.5 \%$ & 57 \\
\hline $\begin{array}{l}\text { If 'yes', do they share } \\
\text { the results with you? }\end{array}$ & $82 \%$ & 18 & $18 \%$ & 4 \\
\hline $\begin{array}{l}\text { Does the person you } \\
\text { care for share any } \\
\text { (other) personal } \\
\text { health data with you? }\end{array}$ & $66.7 \%$ & 52 & $33.3 \%$ & 26 \\
\hline
\end{tabular}

\section{Information Carers Consider Important (Question 9)}

Carers were asked what types of information they consider important to know about the person they care for (table 3). Two-thirds of respondents said "Physiological data"; people most wanted to know weight, blood pressure, blood glucose and body temperature. Most important is mental well-being/mood and calendar. The importance of knowing mood is consistent with the main type of help reported - emotional support. Carers' comments under question 10 indicate why not all are interesting in monitoring physiological health:

- "Physically well, has mental health disability"

- "Some people's health might not get better and you wouldn't want to watch them and recognise they're deteriorating"

- "This would feed existing hypochondria"

- "If it is just the highlighted physiological data (it) has no reference $[s i c]$ to my relatives needs or problems". 
TABLE III. INFORMATION CARERS WOULD LIKE TO KNOW ABOUT THE PERSON THEY CARE FOR

\begin{tabular}{|l|l|l|}
\hline & Response Percent & Response Count \\
\hline Mental well-being/mood & $86.9 \%$ & 73 \\
\hline Calendar & $83.3 \%$ & 70 \\
\hline Safety/security & $77.4 \%$ & 65 \\
\hline Movement/levels of activity & $70.2 \%$ & 59 \\
\hline $\begin{array}{l}\text { Physiological data: blood } \\
\text { glucose, blood oxygen, } \\
\text { blood pressure, body } \\
\text { temperature, heart rate, peak } \\
\text { flow, weight }\end{array}$ & $66.7 \%$ & 56 \\
\hline Indoor temperature & $46.4 \%$ & 39 \\
\hline Other & $14.3 \%$ & 12 \\
\hline
\end{tabular}

\section{Appeal of Self-Monitoring Technology (Question 10)}

Carers were asked if they would be interested in a system that monitors and shares with them the health of the person they care for. The majority of respondents are "Not sure" and a roughly equal number said "Yes" and "No" (table 4).

TABLE IV. IS A HOME MONITORING SYSTEM OF INTEREST TO CARERS?

\begin{tabular}{|l|l|l|}
\hline & Response Percent & Response Count \\
\hline Yes & $22.6 \%$ & 19 \\
\hline No & $21.4 \%$ & 18 \\
\hline Not sure & $56.0 \%$ & 47 \\
\hline
\end{tabular}

The main reasons for being interested are:

- To be better informed e.g. "Would be able to seek help before a crisis takes place"

- To have peace of mind e.g. "To have peace of mind about their health and share progress with doctor"

- To regularly check-in e.g. "I would be able to check regularly but would depend on cost".

The main reasons for not being interested are:

- Cost e.g. "Can't afford it!"

We did not include a cost. Concerns over cost reflect the financial impact of caring - many carers give up work to care full-time.

- The system is not needed e.g. "My grandson has epilepsy so to my knowledge there is nothing that can monitor that".

The main reason for not being sure was there was not enough information to go on e.g. "Need more info on it if it's suitable for my relatives needs".

\section{E. Carers' Comments}

There was a space for comments at the end of the survey, and we asked specifically for carers' views on the benefits of regularly sharing health information. Comments include:

- "Just nice to know"

- "The value lies in knowing what is happening to the cared for, so the carer can better help, know what to watch for, when to seek outside help, and generally help to support the one being cared for"

- "By sharing information many issues become more clear and easier to understand and gives the confidence to care in a better way"
- "Sharing knowledge that is relative to a patient's illness gives people a better understanding why the person is the way they are and why they have the problems they have this hopefully can improve a patient's care"

- "The carer needs to be aware of health information to enable to deliver the best care possible".

Some of the comments relate directly to travel and distance difficulties:

- "This is an absolutely ideal idea. Most of the time you have to travel a lot to get info. I have to travel for prescriptions, use of library, doctors appointments etc. I live in a village, with sparse public transport. Many thanks. Good luck!"

- "To help her with her health and try to avoid so many trips to hospital which cost us money"

- "This would have been handy for me when my husband first came home from hospital and needed to be monitored a lot. To have this information at hand would have saved a lot of emergency call outs"

- "Regular home check ups would be less anxiety for son that I care for, gets very agitated at hospitals or GP surgery".

In summary, we found that: for some carers, it is helpful to know the physiological health of the person they care for; people are using self-monitoring products in their own home; and most people are comfortable sharing personal health information with loved-ones and friends. Three people had privacy concerns e.g. "Bit invasive to relative's privacy".

\section{DESIGN GUIDELINES}

We distilled a list of design guidelines for home monitoring technology from the survey findings and a follow-up discussion at a Moray Carers Forum meeting. This primarily involved identifying and confirming themes based on the anecdotal qualitative feedback and the percentage feedback on questions relating to sharing health information and information carers consider important. This list informed the basic structure and functionality of our system.

- Data: the system needs to collect and store vital signs measurements, mood, and calendar information

- Sharing: the data needs to be shared with carers, and presented in an easy to understand format

- Connectivity: the data collection unit needs to connect to a central database on the internet to send and receive (share) information. E.g. one unit can be in the carer's home and one unit in the home of the cared-for with data shared between the two units

- Real-time: data entered on one unit must be immediately available on all units that it is linked to - if the information is store-and-forward, there is potential for creating a false sense of security for distant carers 
- Cost: the system needs to be affordable to people who live on a low income or government benefits. Or, made available via the health system; one carer commented that she would not purchase anything that she felt should be freely available due to health contributions she has paid during her lifetime

- Accessibility: the user interface (typesize, button size) needs to be accessible and straightforward to use to older people, including those with reduced dexterity e.g. arthritic fingers

- Aesthetic: The design of the system needs to be sensitive to the domestic environment and suitable for all ages. One carer commented, "Too many "gadgets" confuse elderly". At the other end of the age scale, the system needs to be attractive to children and teenagers.

\section{SYSTEM DESCRIPTION}

Based on the design guidelines presented above, we are developing a home monitoring system that will allow people to record, track, and share their physiological health (e.g. weight), mood and calendar events.

The main difference with current home monitoring systems is that our system is primarily intended for use within informal support networks, connecting an individual and their carer rather than andividual and a professional paid care worker such as a doctor or nurse. However, it will be possible to email health information to the GP (general practitioner) practice, as advised.

The system will be made available, at no cost to the user, on a long or short-term basis via the health system. This will ensure that threshold values for vital signs measurements are set correctly, and that people understand what to look for and what action to take, e.g. email the practice if a measurement is above or below set limits.

Information will be entered and displayed on an 8-inch colour touchscreen. Each unit will be usable by more than one person and will be configured to share information among individuals and their carers. There are two main scenarios of use. Where a carer shares the same household as the person they care for, one unit only is needed. A carer can use the unit to monitor their own health as well as the health of the person, or persons, they care for. If a carer lives at a distance, one unit can be in the home of the carer and one unit in the home of the cared-for. Either way, both carer and cared-for can see each other's information i.e. information is shared within the network.

The system is at early prototype stage. We have mapped out the basic structure and functionality, designed the look and feel, and informally tested the usability of mock-ups with potential users. The exact hardware and software specification is currently being resolved. The software application will be written in C-Sharp language and run on Windows. Next steps include consulting our health professional contacts in Moray regarding applicable guidelines and interoperability issues. We also need to consider the ongoing management of the system, including technical support to help users deal with system problems.

\section{USER INTERFACE DESIGN}

The design of the user interface has been iterative, involving testing and refining the usability and graphical style of mock-ups with a range of potential users, including two younger carers (18 years).

Each unit will be set up as single or multi-user. The display is intended to be 'always-on' and easy to monitor. Traffic-light colour coding gives a glanceable indication of current health status; green - everything is fine; amber one or more readings are borderline; red - one or more readings are outside the threshold (Fig. 1). The button size and spacing, and the typeface and size are suitable for older adults, in order to ensure that the monitor is accessible to the largest number of people [9].

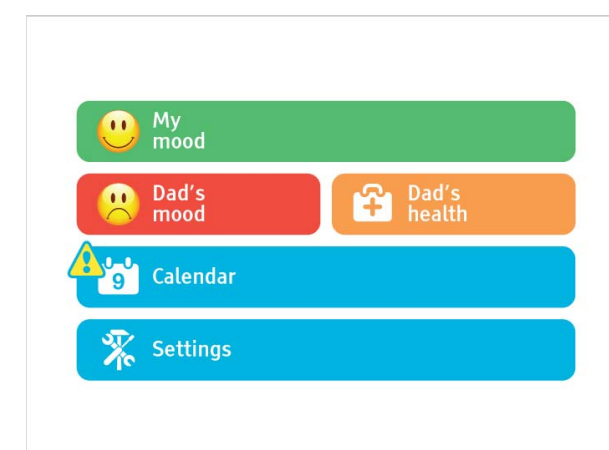

Figure 1. Home page: traffic-light colour coding and smiley faces gives a glanceable indication of current mood and health status.

Users will be able to monitor their mood and/or physiological health. The main mood page will list the current day's entries and any notes that users have written using an on-screen keyboard. The main health page will list those vital signs being monitored along with the current day's readings and notes (Fig 2).

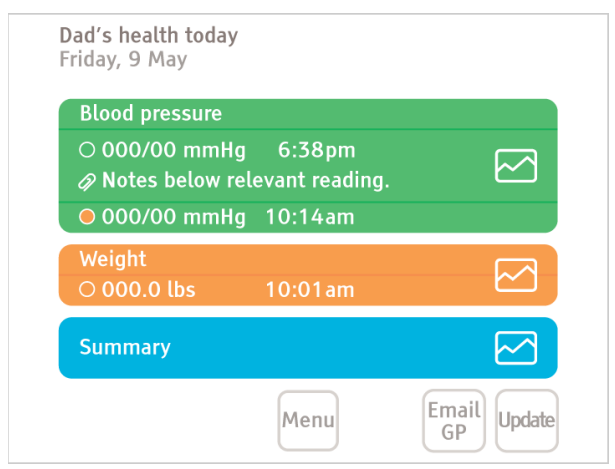

Figure 2. All monitored vital signs are listed with the current day's readings and any notes.

Users will be able to enter a new reading, view trends (history) graphs, compare graphs e.g. mood and weight, and email their GP. Users will be advised by a health 
professional when the unit is made available as to when they should email their GP practice. Carers told us that the ability to send a compiled health record, or diary, to their GP is extremely useful. One carer recounted how he and his wife monitored her blood pressure and pulse three times a day for a week. He wrote all the readings down and was embarrassed to present the doctor with a handful of "scrappy pieces of paper" to sift through.

Trends graphs will allow users to track mood and physiological health over time (Fig. 3).

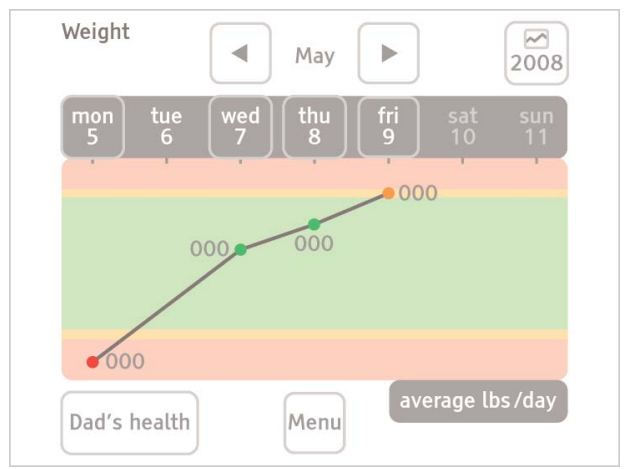

Figure 3. Trends graphs allow users to track health over time and reflect on patterns in their day-to-day life.

In visualising change, the graphs will help users to confirm their own suspicions or feelings about changes in health status e.g. gradual loss of weight, which can reduce anxiety. Potentially, users will be able to gain insight into what affects their mood and health. By default, the graph will show a week-to-view and plot the average value per day; users will touch a particular day e.g. "thu 8 " for full details, including any notes. A (current) year graph will be available.

Physiological health. The system will support a range of measurements including weight, blood pressure and blood glucose. Readings will be manually entered onto the system. This means that people can use their own products e.g. weighing scales. The disadvantage is that although the software will check for erroneous entries, e.g. an unfeasible value, people may incorrectly enter readings. We will explore measuring devices with USB and wireless connectivity to reduce the potential for mistakes.

Personal thresholds for each parameter will be set by a health professional when the monitor is made available. This will ensure that users know their threshold values (or those of the person they care for) and understand if the number shown - the measurement - is above, below or within acceptable/safe limits. Traffic-light colour coding provides redundancy.

Mood. In our discussions with carers, we found that a smiley faces scale is the preferred way to enter mood. The faces are rated 1-5 with face 3 indicating no overall effect (Fig. 4). A recurring theme has been the potential for the display to be somehow responsive to the user's current mood, e.g. to lift mood. We are exploring this possibility.

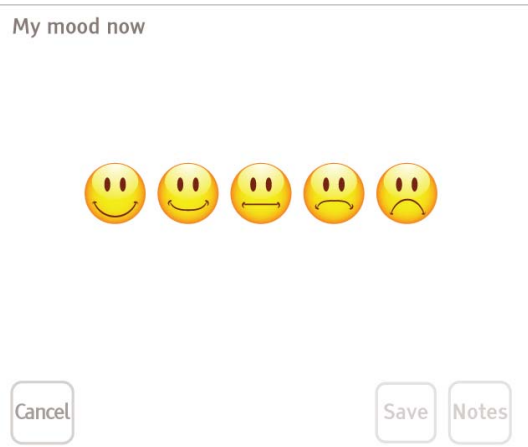

Figure 4. Users select a smiley face to reflect their current mood.

Calendar. Users will be able to enter events in a calendar by touching the relevant day (Fig. 5). Options available for each event include: time, title (includes 'hot keys' for regular events such as doctors and chiropodist), and repeat. The repeat function is useful for medication reminders and other events that happen on a recurring basis - a prompt will appear on the home page. Carers told us that calendar information is important for scheduling care, and automatic reminders are useful because both they and the people they care for can forget appointments and other events e.g. if the carer is under stress or the cared-for has memory problems.

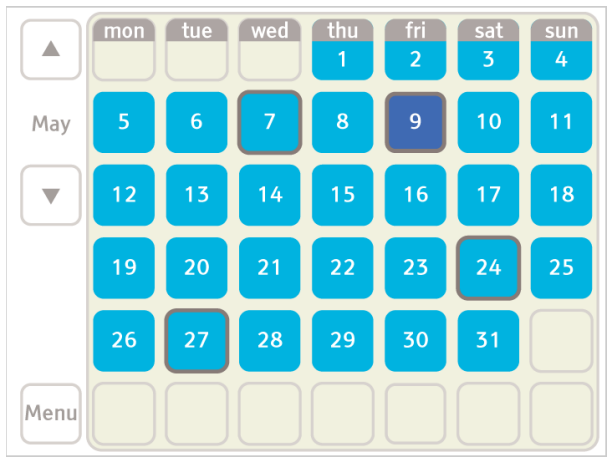

Figure 5. A shared calendar facilitates reminders and organising care.

Settings. There are two settings: 'Accounts' and 'Thresholds'. It will be possible to add, modify (rename account names), or delete user accounts, and determine whom the information will be shared with. The threshold settings will include the full list of vital signs that can be monitored. If an item is activated (ticked), it will become possible to enter threshold values and monitor that vital sign. Settings will be initialised by a health professional.

\section{RELATED WORK}

\section{A. Home Monitoring Systems}

Our system is based on current home monitoring systems such as the "Telehealth Vital Signs Monitor" by Telemedcare [11], 'Doc@Home HealthHUB” by Docobo [6] and "Health Buddy" by Health Hero [8]. Physiological data is captured and stored on a home hub, and forwarded to a database via a telephone or broadband line. The main 
difference with our system is that it is proposed and visually designed for situations where the patient has a carer - the focus is on facilitating information sharing between carers and the people they care for, rather than individual use. The information will be sent to a health professional as advised, rather than on an automatic and regular basis. Potentially, people will be encouraged to better self care, and carers will be kept informed.

\section{B. Glanceable Displays}

Glanceable displays enable users to understand information quickly and easily. E.g., "The CareNet Display" [3] is an interactive digital picture frame that augments a photograph of an older relative with information about his or her daily activities. The display is located in the carer's home to help with coordination of care; the elder does not use the display. Our system is similar in that it also has two modes of use: ambient and interactive. The main screen acts as an ambient display, where people can get a general idea of health status with a quick glance. And, people can touch the buttons for detail. However, our focus is on making the information accessible to all concerned, and supporting carers' health as well as the health of the cared-for person.

\section{Websites}

Increasingly, people are using health community websites, trading some privacy for support and motivation. E.g., "Healthvault" [10] allows a person to upload and store their personal health information and decide who can see the information such as a relative. Our approach differs in that information is available at a glance, without requiring time to turn the computer on and load a website. From a carer perspective, this is important because their role can be timeintensive, involving regular check-ins. One carer commented it's "Useful to have knowledge to hand" e.g. to know the cared-for person's mood on walking in through the door. However, our survey did not ask carers about internet access at home and their experience of using online information. Potentially, a web interface is a convenient solution for some people e.g. carers who continue working or distant carers. However, our software application will run on other devices running Windows and can be ported to the web. Based on further research, a future version could allow users to record, store and access information online.

\section{CONCLUSIONS AND NEXT STEPS}

The number of people requiring care is likely to grow; people are living longer and increasingly living alone. Unpaid carers make an important contribution to society by providing care to loved-ones and friends who are ill, frail or have a disability. However their own health can suffer: carers often focus on the needs of the person they are caring for and neglect their own needs; and the carers' role is often misunderstood or ignored by the health service. This is detrimental to the health of the carer and the cared-for person, and the health system.

This paper has presented research on the importance of considering the role of the carer in the design of new healthcare technology to support people to self care. Our contribution is a set of design guidelines for home monitoring systems, which is extracted from findings from a carers survey on sharing health information and a follow-up discussion at a carers forum. We used these guidelines to design a home monitoring system that will allow people to record and track physiological health, mood and calendar events, and share this information with their carers. Carers can also use the system to monitor their own health. Potentially, the system can support self care, and carers' in their caring role by helping to keep them well and better informed about the health of the person they care for. We informally tested the usability of mock-ups with potential users and health and social care professionals. Feedback has been consistently positive, but usability testing with a working prototype in people's homes is needed to find out if the system is feasible and acceptable. We are currently working on the hardware and software specification in order to build a working prototype.

\section{ACKNOWLEDGMENT}

We thank the The Princess Royal Trust Moray Carers Project and carers in Moray.

\section{REFERENCES}

[1] Carers UK, "In poor health: the impact of caring on health", 2004, Accessed 3 September 2008, http://www.carersuk.org/Policyandpractice/Research/Healthimpactof caring/1201185222

[2] Carers UK, "The facts about carers", Accessed 3 September 2008, http://www.carersuk.org/Employersforcarers/Thebusinesscase/Thefac tsaboutcarers

[3] Consolvo, S., Roessler, P., Shelton, B. E., "The CareNet Display: lessons learned from an in home evaluation of an ambient display", UbiComp 2004, 2004, pp. 1-17.

[4] Department of Health, "Public attitudes to self care - baseline survey, February 2005", 2005, Accessed 3 September 2008, http://www.dh.gov.uk/en/Publicationsandstatistics/Publications/Publi cationsPolicyAndGuidance/DH_4111260

[5] Department of Health, "Research evidence on the effectiveness of self care support", 2007, Accessed 3 September 2008, $\mathrm{http} / / /$ www.dh.gov.uk/en/Publicationsandstatistics/Publications/Publi cationsPolicyAndGuidance/DH_080689

[6] Docobo, “doc@HOME”, Accessed 3 September 2008, http://www.docobo.co.uk/

[7] General Register Office for Scotland, "Mid-2007 population estimates Scotland", 2008, Accessed 3 September 2008, http://www.gro-scotland.gov.uk/statistics/publications-anddata/population-estimates/mid-2007-population-estimatesscotland/index.html

[8] Health Hero, "Health Buddy", Accessed 3 September 2008, https://www.healthhero.com/

[9] Jin, Z. X., Plocher, T., and Kiff, L., "Touch screen user interfaces for older adults: button size and spacing", Universal access in HCI, 2007, pp. 933-941.

[10] Microsoft, "HealthVault", Accessed 3 September 2008, http://www.healthvault.com

[11] Telemedcare, "Telehealth Vital Signs Monitor", Accessed 3 September 2008,

http://www.telemedcare.co.uk/vitalsigns.html 